\title{
Avaliação energética de um edifício de serviços: Escola Superior Aveiro Norte, Portugal
}

\author{
Energy analysis of a public services building: North Aveiro \\ School, Portugal
}

\section{J osé Carlos Martins Ramalho Nelson Amadeu Dias Martins}

\section{Resumo}

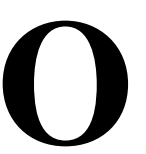

objetivo deste trabalho é realizar uma avaliação energética da Escola Superior Aveiro Norte (ESAN), situada no município de Oliveira de Azeméis (Portugal). Esse edifício possui tecnologias de climatização pouco convencionais em Portugal, como bombas de calor geotérmicas associadas a piso radiante e ventilação, com pré-aquecimento de ar, utilizando painéis solares e recuperação de calor. Apesar de visarem a melhoria das condições de conforto térmico com baixo consumo energético, podem não garantir essas condições. Modela-se o edifício com a ferramenta computacional de simulação dinâmica DesignBuilder, introduzindo-se dados relativos a envoltória, iluminação, ocupação, equipamentos e sistemas de climatização. A partir da modelização do edifício e da análise dos resultados, verificou-se que a heterogeneidade da área de superfícies envidraçadas e das cargas térmicas entre os diferentes espaços internos, conjugados com a climatização feita por três sistemas partilhados de aquecimento, ventilação e ar condicionado, causa grandes desequilíbrios térmicos e dificuldades em garantir condições de conforto térmico no edifício. Este estudo poderá ser aplicado em outras tipologias de edifícios, especialmente aqueles situados em regiões com grandes amplitudes térmicas diárias e/ou sazonais, com necessidades de aquecimento e arrefecimento. Além disso, demonstra-se que, com bom planejamento, é possível projetar edifícios com eficiência energética e conforto térmico.

Palavras-chave: Edifício público. Eficiência energética. Climatização. Bombas de calor geotérmicas. Piso radiante.

\begin{abstract}
The goal of this paper is to undertake an energy performance analysis of the North Aveiro School (ESAN) building, located in the municipality of Oliveira de Azeméis (Portugal). This building uses HVAC technologies that are unusual in Portugal, such as ground source heat pumps associated with floor heating and ventilation with air preheating, using solar panels and heat recovery. Although these technologies were intended to provide thermal comfort conditions with low energy consumption, they have failed to do so. A thermal dynamic simulation of the building was made using the DesignBuilder software, including features such as envelope, lighting, occupancy, equipment and HVAC systems. Based on the building model and the analysed results, the researchers found that the heterogeneity of the glazed surfaces, the the differences in thermal loads in the different rooms, and the three shared cooling systems cause major thermal imbalances and difficulties to provide thermal comfort conditions in the building. This study can be applied to other buildings, especially buildings located in regions with broad daily and/or seasonal thermal amplitudes, which need both heating and cooling. This study is important because it demonstrates that with good planning, it is possible to design buildings with energy efficient thermal comfort strategies.
\end{abstract}

Keywords: Public building. Energy efficient. HVAC. Ground source heat pump. Radiant floor.

RAMALHO, J. C. M.; MARTINS, N. A. D. Avaliação energética de um edifício de serviços: Escola Superior Aveiro Norte, 335 Portugal. Ambiente Construído, Porto Alegre, v. 19, n. 4, p. 335-348, out./ dez. 2019. 


\section{Introdução}

Segundo Staniaszek et al. (2014), cerca de 40\% dos consumos totais de energia na Europa são dos edifícios, sendo a maior parte dessa energia gasta em climatização. Além disso, Portugal ainda importa três quartos da energia elétrica que consome (DIRECÇÃO-GERAL..., 2016), o que significa um impacto negativo na economia. De acordo com a Comissão Europeia (COMISSÃO..., 2016a), os sistemas de aquecimento e água quente sanitária (AQS) representam 79\% da energia total gasta na Europa. Apesar de uma porcentagem pequena, o consumo elétrico do arrefecimento está aumentando no setor doméstico e, também, na indústria alimentícia, devido às alterações climáticas. Além disso, 84\% da energia usada em aquecimento e AQS ainda provém de fontes não renováveis. Em Portugal, o Inquérito ao Consumo de Energia no Setor Doméstico (INSTITUTO...; DIRECÇÃO-GERAL..., 2010) revelou que 23,5\% do consumo energético foi com a AQS e 21,5\% com o aquecimento (em que a madeira foi o combustível mais utilizado, representando $68 \%$ do total). Já a iluminação representa 4,5\% dos consumos totais do setor doméstico e as casas com ar condicionado para arrefecimento representam apenas $0,5 \%$ dos consumos. Fica a ressalva de que os dados são do início da década de 2010 e as necessidades humanas, a tecnologia e o clima tiveram rápidas alterações, podendo o panorama atual ser diferente.

Os elevados consumos energéticos levaram à alteração das leis vigentes em Portugal, os Decretos-Lei n. 79 e 80/2006, de 4 de abril de 2006, sendo o primeiro relativo aos sistemas de climatização e o segundo relativo ao comportamento térmico dos edifícios. O DecretoLei n. 118/2013, de 20 de agosto (Sistema de Certificação Energética dos Edifícios - SCE) levou a alterações de exigência relativamente ao consumo energético dos sistemas de climatização, colocando a qualidade do ar interior (QAI) em segundo plano. Um exemplo disso foi a extinção das auditorias de QAI obrigatórias e o aumento do nível máximo permitido de $\mathrm{CO}_{2}$ de 900 ppm para 1.250 ppm. Além disso, estipulou-se que a partir de 2018 os novos edifícios de serviços e a partir de 2020 os restantes edifícios construídos deverão ter um balanço de emissões que tenda para a neutralidade (Near-Zero Emissions Building - NZEB), o que significa que deverão produzir a maior parte da energia que consomem, utilizando fontes renováveis, conforme a Diretiva do Desempenho Energético dos Edifícios (EPBD) 2010/31/C (COMISSÃO..., 2010). No entanto, a EPBD não estabelece o nível de aproximação ao zero do balanço energético dos edifícios, cabendo a cada estado encontrar uma definição própria para a designação (KURNITSKI, 2013).

Segundo o CE (COMISSÃO..., 2016b), três em cada quatro edifícios existentes não atendem aos requisitos de eficiência da $E P B D$ e a taxa de renovação dos edifícios situa-se entre 0,4\% e 1,2\%. Entretanto, dados do BPIE (BUILDING..., 2014), que também levam em conta os edifícios ineficientes construídos depois de 1990, mostram que a porcentagem de edifícios que não atendem aos requisitos de eficiência é, na verdade, superior a 97\%. Em Portugal, o parque edificado é antiquado, e, segundo dados do último censo (INSTITUTO..., 2011), a idade média das habitações era de 38 anos. Além disso, de acordo com o INE (INSTITUTO..., 2018), o número de habitações novas construídas passou de 124.297 (em 2002) para apenas 8.931 (em 2017). Tan et al. (2018) e Power (2008) afirmam que, por questões ambientais, sociais e econômicas, é preferível, na maioria das vezes, reabilitar os edifícios existentes em vez de construir novos, a fim de torná-los mais eficientes e confortáveis. Entretanto, apesar da urgência em reabilitar edificações para melhorar a eficiência e as condições de conforto, é difícil fazê-lo. Um modelo que combina o conceito NZEB com um custo idêntico ao de uma construção tradicional é o da certificação Passivhaus Institut (2016), que afirma ser possível reduzir de $70-90 \%$ o consumo energético em edifícios reabilitados, melhorando simultaneamente as condições de conforto térmico. No entanto, Firląg e Piasecki (2018) observaram que para se conseguir maior redução de consumo energético o resultado financeiro nem sempre é viável, especialmente se o valor da energia for baixo. Salienta-se, então, a importância de garantir a eficiência do edifício logo desde a fase de desenvolvimento do projeto.

Como tal, o objetivo principal deste estudo é efetuar a primeira avaliação energética de um edifício de serviços, construído recentemente (projeto de 2012), considerando-se o moderno partido arquitetônico e a arrojada tecnologia de climatização, a fim de verificar e melhorar a sua eficiência energética.

\section{Materiais e métodos}

\section{Objeto de estudo}

O objeto de estudo é um Grande Edifício de Serviços (GES), com uma área superior a $1.000 \mathrm{~m}^{2}$, de acordo com o SCE (LABORATÓRIO..., 2013). Nesse edifício funciona, desde 2014, a Escola Superior Aveiro Norte (ESAN), que é um polo da 
Universidade de Aveiro (UA), Portugal, no município de Oliveira de Azeméis (Figura 1). Nessa escola são lecionados cursos técnicos superiores e licenciaturas, com aulas práticas, nas áreas de tecnologias de produção, design, desenvolvimento de produto, tecnologias e sistemas de informação e comunicação (ESCOLA..., 2016). Além das salas de aulas e das salas dos professores, o edifício possui equipamentos industriais de grande porte, grande consumo energético e produção de calor, como máquinas de injeção de moldes ou de prototipagem. A escolha desse objeto de estudo justifica-se pelas aparentes deficiências em nível de conforto reportadas pelos ocupantes, que contrariam o intuito dos sistemas de climatização que o equipam.

O edifício da ESAN localiza-se a uma altitude de 206 m (Fonte: software Google Earth). Dispõe de uma área coberta de $2.700 \mathrm{~m}^{2}$ e utiliza sistemas de climatização avançados, entre os quais: piso radiante para distribuição da água aquecida ou arrefecida por três bombas geotérmicas de calor, painéis solares para produção de AQS e painéis solares para pré-aquecimento do ar induzido no edifício, ambos com orientação sul (ENERES, 2010). A fachada sul é envidraçada e as salas interiores têm também dispositivos zenitais com orientação a sul (Figura 2). A fachada norte tem uma área envidraçada muito menor (em comparação com a fachada sul), e a fachada oeste tem apenas portas envidraçadas que dão acesso a uma varanda, junto à cafeteria. Na Figura 3 são visíveis ainda seis laboratórios: de materiais, de mecatrônica e eletrônica, de modelagem, de prototipagem, de projetos e de instrumentação; e duas oficinas de processos industriais: de metais e de polímeros (ESCOLA..., 2016).

\section{Método}

A metodologia adotada neste trabalho de investigação segue a mesma estrutura de uma auditoria energética. Conforme Almeida et al. (2007), são definidas quatro fases básicas: planejamento, visita às instalações, tratamento dos dados e elaboração de um relatório.

No que diz respeito ao planejamento, incialmente foram verificados os projetos de arquitetura e construção, os dados técnicos do edifício e os equipamentos de climatização. Conhecendo a localização do edifício, foi possível obter os dados climáticos, que foram integrados no software de simulação, e com as peças desenhadas foi criado o modelo tridimensional do edifício.

Figura 1 - Localização da zona do país onde o edifício se encontra e geração de dados climáticos utilizados no programa de simulação dinâmica

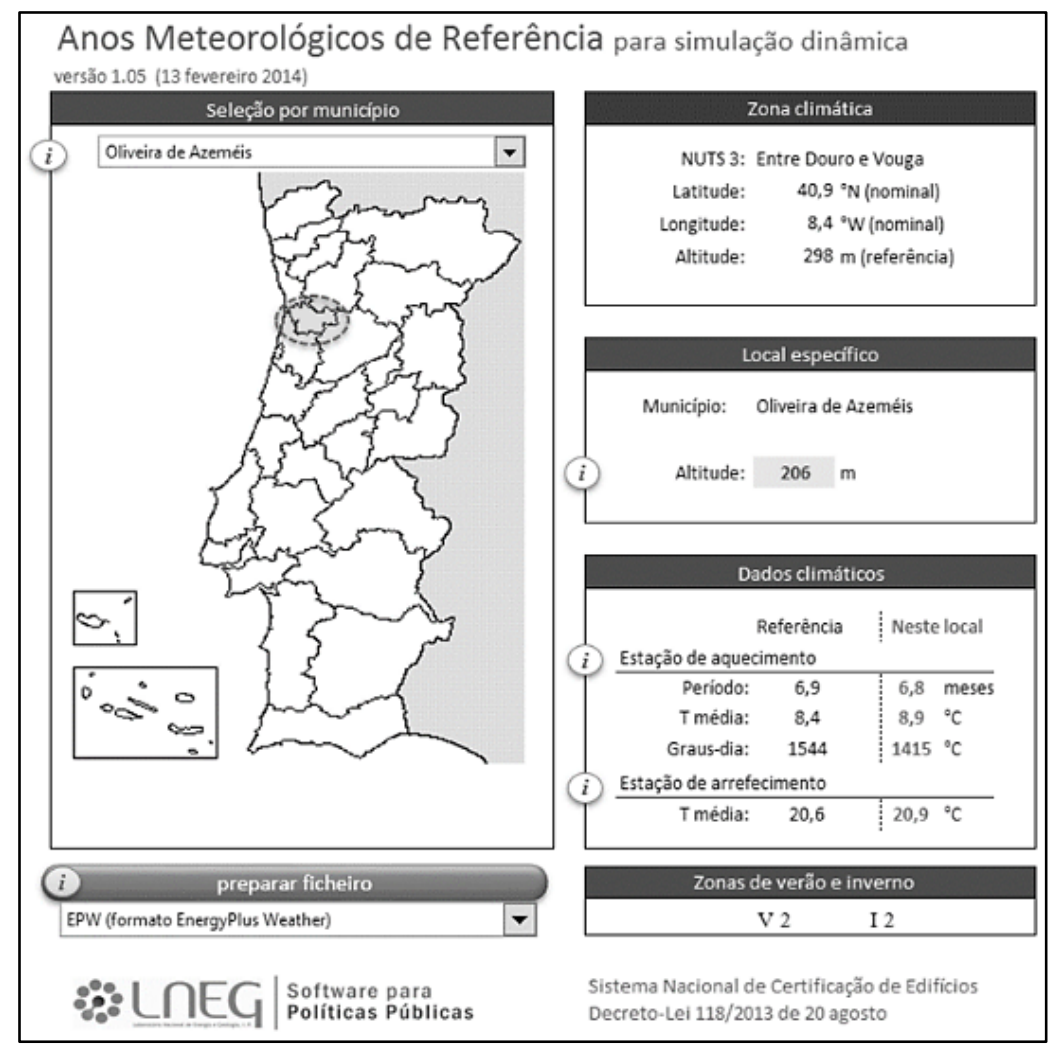

Fonte: LNEG (Laboratório Nacional de Engenharia Geológica) (2013). 
Figura 2 - Vista da fachada sul do edifício

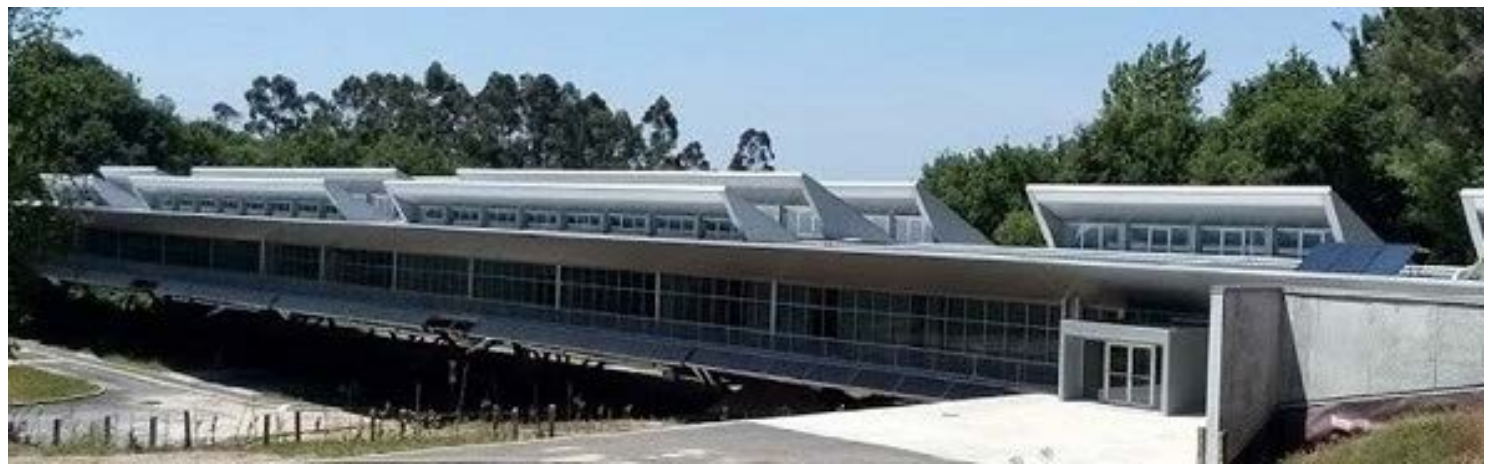

Fonte: Escola Superior Aveiro Norte (2016).

\section{Figura 3 - Planta baixa e zoneamento do edifício}

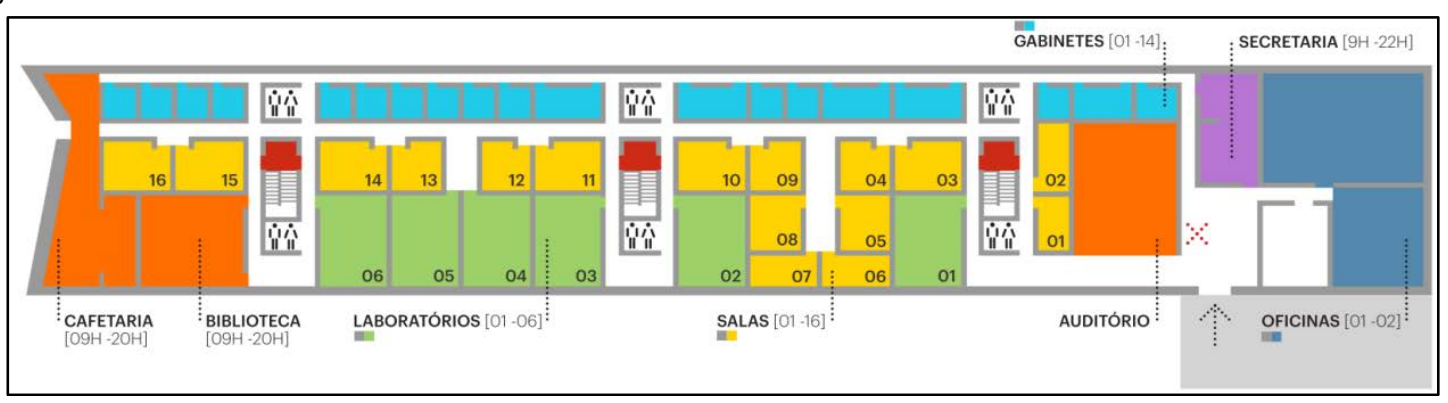

Fonte: Escola Superior Aveiro Norte (2016).

Na segunda fase foram efetuadas duas visitas no edifício (uma em maio e outra em novembro de 2016), a fim de se obter o máximo de informações relevantes para introduzir na simulação. Os dados recolhidos referem-se às atividades nas salas, perfis de ocupação (número de pessoas, dias e horários de ocupação) e utilização dos equipamentos e dos sistemas de climatização (ALMEIDA et al., 2007).

Na terceira fase foi realizada a simulação do modelo calibrado do edifício, sendo a simulação desse modelo original comparada com um modelo de referência, de forma a caracterizar a classe energética do edifício avaliado. Finalmente, os resultados da simulação são analisados, indicandose os problemas e as causas para melhoria na eficiência energética e na qualidade de ar interior. A criação do modelo de simulação é um processo complexo e exaustivo. Para afinar a verificação dos resultados foram realizadas duas visitas ao edifício, sendo uma antes e outra posterior à simulação.

\section{Modelagem do edifício}

O primeiro passo para a modelagem do edifício através da ferramenta DesignBuilder é a introdução dos dados climáticos referentes à localização do edifício. Dado que a Portaria n. 349-D.2013, de 2 de dezembro (Regulamento de Desempenho dos Edifícios de Comércio e Serviços - RECS), especifica que para se fazer uma simulação dinâmica multizona "devem ser utilizados os dados climáticos disponibilizados, para este efeito, pela entidade gestora do SCE”. Foi extraído da página do LNEG (LABORATÓRIO..., 2013) um arquivo de Excel, a fim de criar um arquivo (*.epw) de dados climáticos, compatível com o DesignBuilder, com base no município e na altitude onde se encontra o edifício (Figura 1).

O passo seguinte é a modelagem tridimensional do edifício, cujos dados mínimos especificados pelo RECS e relativos ao levantamento dimensional são: tipo de espaço; altura do pé-direito; áreas em contato com o solo; áreas totais do pavimento, da envoltória vertical e horizontal, exterior e interior, opaca e envidraçada. Para tal, realiza-se um levantamento dimensional através das plantas e dos cortes disponibilizados pelos Serviços de Gestão Técnica e Energética da UA. Ferramentas de modelagem do DesignBuilder foram utilizadas para criar o modelo 3D do edifício, decalcando a planta $2 \mathrm{D}$, que foi importada para o programa, para auxiliar a modelagem. E finalmente foram introduzidos os dados relativos à constituição das soluções construtivas utilizadas no edifício, presentes na documentação fornecida.

Posteriormente foram inseridos os dados relativos aos perfis de utilização. Muito embora alguns 
desses dados não tenham sido precisos, eles tiveram de ser arbitrados e estimados. Por exemplo, a potência calorífica que os equipamentos emitem para o meio ambiente não coincide com a potência nominal indicada. Nesses casos, arbitrou-se um fator de potência (fração da potência nominal), para que os valores de temperatura tivessem maior aproximação da realidade na simulação. Objetivando-se afinar os resultados da avaliação, foi necessário calibrar o modelo da simulação e comparar os resultados com o consumo energético real de uso do edifício. Segundo O’neill e Eisenhower (2013), o processo de calibragem de modelos de simulação de edifícios é complexo, exaustivo e frequentemente necessita de conhecimento especializado e de maior aprofundamento na avaliação. Na avaliação do consumo energético do edifício é necessário ter um histórico de consumos de, no mínimo, um ano completo. Segundo Yoon, Lee e Claridge. (2003), o ideal seria fazer uma média dos consumos a partir do histórico de 4 anos. O modelo deve ser afinado iterativamente até que os resultados estejam dentro de uma margem de $10 \%$ em relação aos consumos medidos (PRATT, 1990; KAPLAN et al., 1992). No caso particular deste trabalho, sendo os dados relativos a dois meses, não foi possível fazer uma calibragem do modelo. Devido a esse fato, foi apenas efetuada a alteração das potências caloríficas emitidas pelos equipamentos, até que os valores das temperaturas interiores simuladas fossem plausíveis.

Tendo sido feita a modelagem, foram introduzidos os dados referentes aos equipamentos e luminárias existentes em cada sala (tipo de equipamento, potência e horário de utilização), a ocupação (número de pessoas, tipo de atividade e horário de ocupação), tal como estipulado no Despacho n. 15.793-E/2013 de 3 de dezembro. A fim de reduzir o tempo de simulação do modelo, foram feitas simplificações no zoneamento, ao reunir as zonas que apresentem o mesmo tipo de ocupação, equipamentos e que são climatizadas pelos mesmos sistemas, tratando-as como uma única zona. Por exemplo, 11 salas de professores, duas salas da secretaria, salas de aulas e espaços adjacentes foram reunidos numa só zona.
A fase seguinte consiste na criação de um modelo de referência para a certificação energética do edifício, com base na determinação da sua classe energética. O objetivo é de efetuar uma comparação de desempenho térmico do modelo original do edifício com esse modelo de referência. Com esse fim, é criado um novo modelo (arquivo de específico de simulação) baseado nas características construtivas do modelo original, substituindo as características da envoltória, sistemas de climatização e iluminação para aquelas incluídas no RECS. Neste estudo, essa fase não foi efetuada, pelo fato de o modelo não ter sido calibrado, tendo apenas sido realizadas comparações entre o modelo-base e cada alteração realizada.

\section{Resultados e análise}

\section{Potência necessária vs. potência instalada}

Considerando-se os sistemas de climatização em Autosize (dimensionados automaticamente para garantir as necessidades de aquecimento e arrefecimento), os resultados mostram maiores necessidades de arrefecimento do que de aquecimento (Tabela 1). Esses resultados podem ser explicados pelo fato de o edifício possuir diversos equipamentos que produzem calor, contribuindo para reduzir as necessidades de aquecimento no inverno e maior necessidade de arrefecimento no verão.

Por outro lado, as bombas de calor geotérmicas têm um rendimento nominal maior no inverno do que no verão, quando o modelo aponta para as maiores necessidades de climatização (ENERES, 2010). Esse fato é causado por uma carência de potência de arrefecimento e de uma reserva de potência de aquecimento em situações críticas de simulação, e que apresentam a mesma ordem de grandeza (Tabela 1), sugerindo que os resultados do modelo possam ser plausíveis. Essa constatação pode ser explicada pelo fato de os modelos utilizados para projetar o sistema de climatização apresentarem pressupostos que divergem do modelo-base deste trabalho, que foi realizado após a construção do edifício, já com os equipamentos em utilização, embora ainda não em plena atividade.

Tabela 1 - Comparação entre a potência instalada e a necessidade de potência simulada

\begin{tabular}{c|c|c|c}
\hline Potência total & P. nominal instalada (kW) & Potência necessária (kW) & Diferença (kW) \\
\hline Aquecimento & 283,58 & 222,55 & $+61,03$ \\
Arrefecimento & 235,00 & 300,52 & $-65,52$ \\
\hline
\end{tabular}


Com o edifício em funcionamento, seria difícil fazer alterações profundas em nível de posicionamento das salas. É possível que a localização de algumas salas não seja a mais adequada. Por exemplo, o Laboratório de Prototipagem está localizado na zona sul do edifício (supostamente a mais quente), existindo nessa sala equipamentos de impressão 3D que emitem elevada energia ( $>2 \mathrm{~kW})$. Na visita de novembro, observouse que um aparelho de ar condicionado portátil estava nessa sala, devido à insuficiência de arrefecimento através do sistema de climatização do edifício. Ao mesmo tempo, as salas dos professores, com menor quantidade de equipamentos geradores de energia calorífica e menor atividade física, estão localizadas na zona norte (supostamente a mais fria) do edifício.

Outra situação crítica é o fato de o projeto do edifício contemplar piso radiante na sala Bastidor 1. Como essa sala precisa ser permanentemente arrefecida, não deveria existir aqui qualquer sistema de aquecimento. Além disso, observa-se na Figura 4 que o Bastidor 1 e a Portaria pertencem ao mesmo circuito, um único espaço que foi posteriormente dividido em dois por uma divisória.

O edifício apresenta um piso radiante cuja distribuição é feita por vários circuitos, com uma válvula manual para cada circuito. Porém, não é possível controlar a temperatura nas diferentes zonas do edifício, pois não existem sensores de temperatura em cada zona nem válvulas atuadas pelo sistema de controle para direcionar o fluxo de água quente às zonas onde é mais necessária e, eventualmente, fechar completamente o fluxo às zonas sem necessidade de aquecimento o que pode ser considerada uma falha na implementação (Figura 5). Para melhor funcionamento, seria necessário montar válvulas controladas eletronicamente pelo sistema e ativar a sua abertura através da informação dada pelos sensores de temperatura à entrada e à saída do circuito. Caso as temperaturas fossem muito próximas, sinal de que o piso radiante não estivesse emitindo grande quantidade de energia, o fluxo de água poderia ser controlado de forma parcial ou totalmente limitada. A fim de controlar a temperatura do piso radiante de forma independente, cada sala ou zona deveria ter o seu próprio circuito e sensores específicos de temperatura do piso radiante e de temperatura do ar interior, em conjunto com uma painel de comando para os ocupantes escolherem a temperatura interior.

Outra solução para melhorar o problema dos locais Bastidor 1 e da Portaria (com temperaturas superiores a $30{ }^{\circ} \mathrm{C}$ no inverno) seria retirar a divisória envidraçada que separa a portaria do átrio, passando a fazer parte do átrio, de forma a poder funcionar independentemente do circuito do piso radiante.

\section{Envidraçados/orientação: heterogeneidade}

Em relação às superfícies envidraçadas, segundo a norma ISO 15099/NFRC, o valor calculado pela ferramenta DesignBuilder para o coeficiente de transmissão térmica (U) é de $1,640 \mathrm{~W} \cdot \mathrm{m}^{-2} \cdot{ }^{\circ} \mathrm{C}^{-1}$. Esse valor é superior ao previsto no projeto de eficiência energética do edifício (ENERES, 2010), 1,4 W.m${ }^{2} .{ }^{\circ} \mathrm{C}^{-1}$, e inferior ao da solução de referência, 3,3 $\mathrm{W} \cdot \mathrm{m}^{-2} .{ }^{\circ} \mathrm{C}^{-1}$ (definida no RECS). Além disso, existem dispositivos de sombreamento interiores, que não são muito eficazes, pois absorvem a radiação solar e emitem a energia armazenada para o espaço interior. Por outro lado, esses dispositivos poderão interferir na funcionalidade das janelas, ao impedir a circulação de ar como também no controle de aberturas, quando necessário o seu fechamento por questão de segurança.

Um exemplo que expressa a heterogeneidade é o das salas 1.3.5 (CET1) e 1.3.6 (CET 2), que são contíguas e semelhantes em utilização, porém os ganhos solares são distintos. Ambas as salas têm janelas voltadas à orientação sul, mas enquanto a primeira (1.3.5) tem as janelas na cobertura, a segunda (1.3.6) tem as janelas expostas na parede sul da fachada, com uma área $418 \%$ superior (Figura 6). Além disso, os ganhos solares são maiores no inverno do que no verão, pelo fato de os dispositivos de sombreamento terem sido concebidos de forma a favorecer a incidência da radiação solar direta no inverno e de proteger a fachada da radiação solar no verão. Entretanto, o fato que distingue as condições das duas salas, é que a sala 1.3.6 tem ganhos solares que ultrapassam o valor de $7 \mathrm{~kW}$, e a sala 1.3 .5 tem ganhos de $1 \mathrm{~kW}$ no máximo, no inverno (Figura 7). No verão os ganhos através das superfícies envidraçadas são inferiores (a $3 \mathrm{~kW}$ e $0,5 \mathrm{~kW}$, respetivamente), ainda assim a diferença é de cerca de 6 vezes.

Apesar dessa diferença nas necessidades de climatização, as duas salas são climatizadas pelo mesmo sistema, constatando-se em temperaturas superiores a $30{ }^{\circ} \mathrm{C}$ em dias ensolarados de inverno na sala 1.3.6, e uma diferença de temperatura da ordem dos $10^{\circ} \mathrm{C}$ na sala 1.3.5. Além desse exemplo, a situação é análoga nas salas de professores e nas salas orientadas ao sul (como, por exemplo, a biblioteca). É impossível garantir o mesmo ponto de ajuste (temperatura pretendida) nas duas salas, tendo essas diferentes orientações e áreas envidraçadas, que são climatizadas pelos mesmos equipamentos. 
Figura 4 - Detalhe de circuito de piso radiante, presente no Bastidor 1

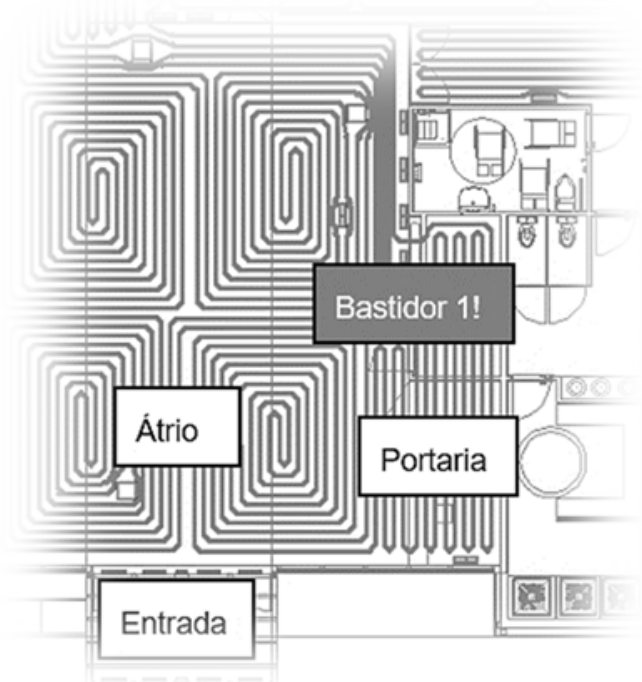

Fonte: Chama (2013).

Figura 5 - Válvulas de abertura e fechamento de caudal no coletor de retorno

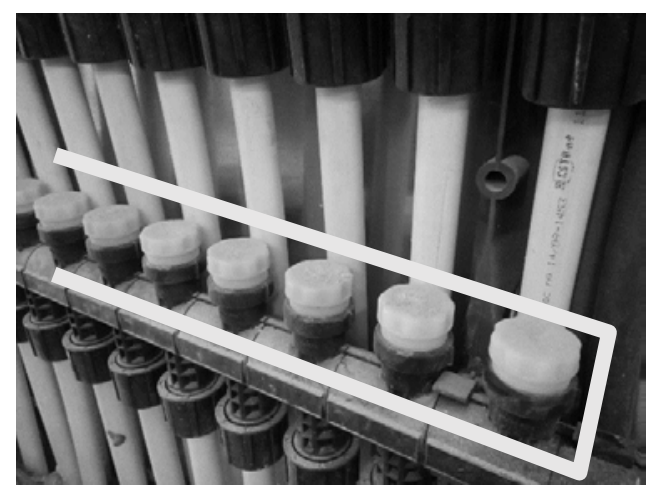

Figura 6 - Localização das salas 1.3.5 e 1.3.6

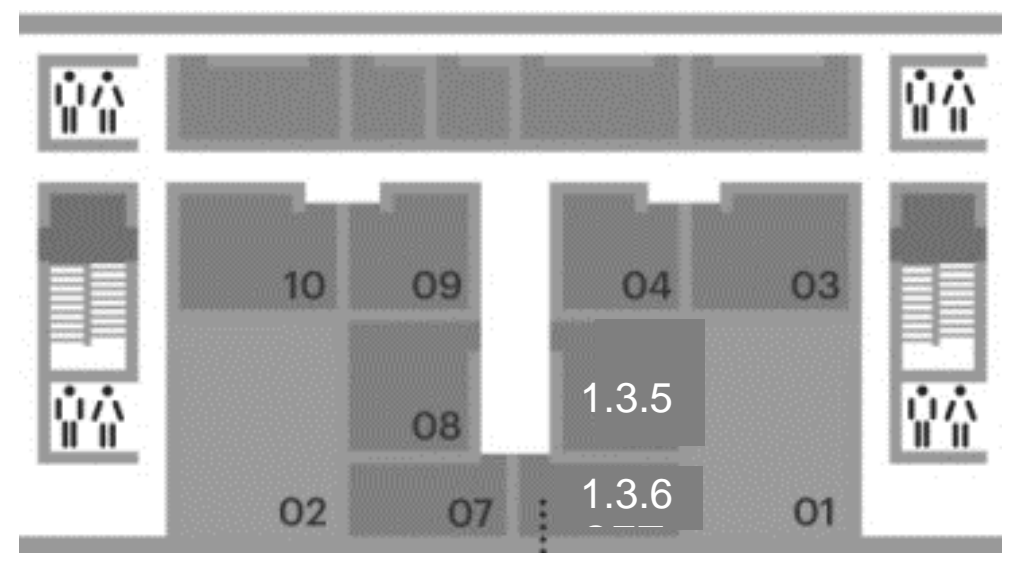

Fonte: adaptado de Escola Superior Aveiro Norte (2016). 
Figura 7 - Ganhos solares pelos envidraçados em (kW) na semana mais fria de inverno, nas salas CET 1 e 2 , respetivamente

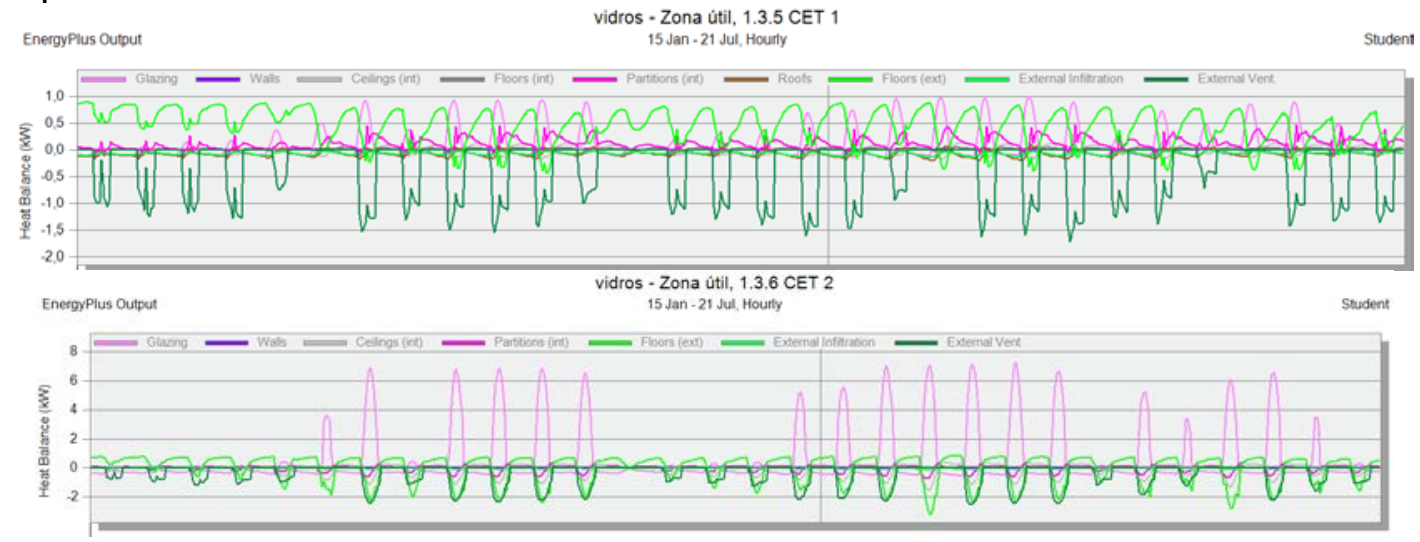

Segundo DesignBuilder (2016), o superaquecimento é um problema frequente em sistemas com pisos radiantes, especialmente em manhãs frias de inverno. Isso é devido à necessidade de aquecimento ser elevada. E, com o passar do dia, com os ganhos solares a emissão de energia aumenta. Torna-se, então, difícil o controle da emissão de calor através do piso, que é também acentuada pelo efeito de inércia térmica do sistema.

Considerando os problemas causados pelo excesso de ganhos solares no inverno nas salas orientadas à fachada sul, necessitando de arrefecimento e aquecimento, sugere-se a montagem de dispositivos de sombreamento com lâminas na face exterior da fachada. Estes permitem diminuir os ganhos solares excessivos e favorecem um melhor nível de luminosidade, assim como a renovação de ar no interior das salas.

Simulou-se o modelo com os sistemas de climatização em Autosize, com base nos cenários seguintes: inicial - com persianas rolô medianamente opacas montadas na face interior (Figura 8) - e final - com venezianas montadas na face exterior em toda a fachada sul, com lâminas metálicas de $80 \mathrm{~mm}$ (Figura 9). Mantém-se o fechamento quando os ganhos solares ultrapassem os $300 \mathrm{~W} . \mathrm{m}^{-2}$, de acordo com o RECS. Os resultados mostram que na portaria (sala com 7,66 $\mathrm{m}^{2}$, limitada pela fachada sul por $5,78 \mathrm{~m}^{2}$ de superfície envidraçada e por uma divisória interior de vidro com $6,40 \mathrm{~m}^{2}$ ), as temperaturas interiores passam de $32{ }^{\circ} \mathrm{C}$ para $20^{\circ} \mathrm{C}$, em uma semana típica de inverno, com temperaturas exteriores de $15{ }^{\circ} \mathrm{C}$ (Figura 9).

\section{Envoltória opaca}

A Tabela 2 mostra a comparação estabelecida entre os coeficientes de transmissão térmica (U) presentes na legislação (RECS) e os coeficientes das envoltórias referidos no DesignBuilder.
Considerando a envoltória opaca vertical exterior, observa-se que a parede que apresenta um desempenho térmico mais desfavorável tem melhor desempenho que a solução de referência. Todos os outros têm um U inferior (com melhor isolamento térmico), tendo o melhor desempenho a parede com $\mathrm{U}$ de $0,448 \mathrm{~W} \cdot \mathrm{m}^{-2} \cdot{ }^{\circ} \mathrm{C}^{-1}$, localizada na circulação. Essa é composta do material Celenit - lã de madeira de abeto mineralizada, rejuntada com cimento Portland cinza - e painel sandwich de alumínio, com alma isolante em poliuretano.

A cobertura apresenta o valor do coeficiente $U$ inferior à solução de referência, o que indica um bom isolamento térmico. Contudo, no piso exterior (constituído por uma laje de concreto de $200 \mathrm{~mm}$, isolada por $20 \mathrm{~mm}$ de poliuretano projetado), o valor do coeficiente U é de $0,922 \mathrm{~W} \cdot \mathrm{m}^{-2} .{ }^{\circ} \mathrm{C}^{-1}$, superior ao valor de referência e apenas $8 \%$ inferior ao valor máximo que é permitido por lei, para o local de implantação do edifício. Observa-se que o isolamento do piso é insuficiente para atender a um bom desempenho térmica, comparando-se os valores do coeficiente U das restantes envoltórias opacas. O menor isolamento pode causar a perda de calor produzido através do piso radiante.

Para corrigir o fraco isolamento da laje de concreto do piso, com vista a diminuir as perdas de calor do edifício, uma medida seria a de aumentar a espessura de isolamento de $20 \mathrm{~mm}$ para $60 \mathrm{~mm}$. Nesse caso o coeficiente de desempenho U do piso seria $0,398 \mathrm{~W} \cdot \mathrm{m}^{-2} \cdot{ }^{\circ} \mathrm{C}^{-1}$, aproximando-se ao nível de desempenho térmico das demais envoltórias opacas do edifício, em torno de $0,4 \mathrm{~W} \cdot \mathrm{m}^{-2} \cdot{ }^{\circ} \mathrm{C}^{-1}$.

Após simulação do modelo na semana mais fria de inverno e considerando essa alteração no isolamento de piso, aquecendo-se o piso radiante, verifica-se que os ganhos térmicos através do piso aumentam entre $7 \%$ e 17\% (Tabela 3), ou seja, haverá redução na emissão de calor através da laje de concreto. 
Figura 8 - Simulação anual das temperaturas e ganhos solares através das superfícies envidraçadas, com persianas rolô interiores

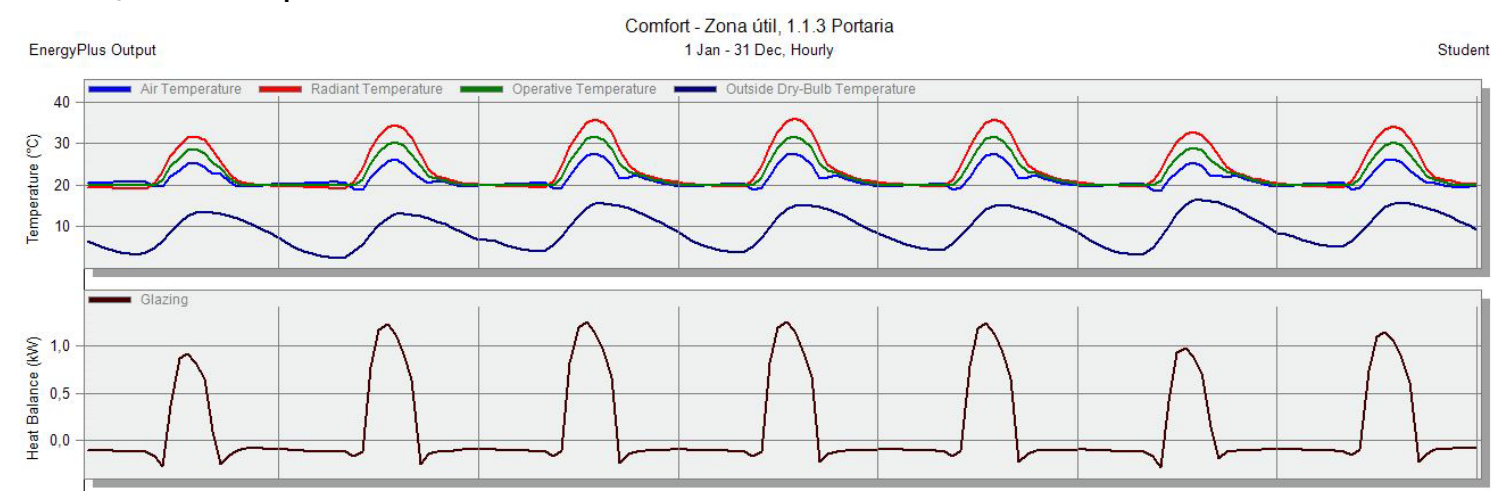

Figura 9 - Temperaturas e ganhos solares pelos envidraçados, simulados em uma semana típica de inverno, com venezianas exteriores

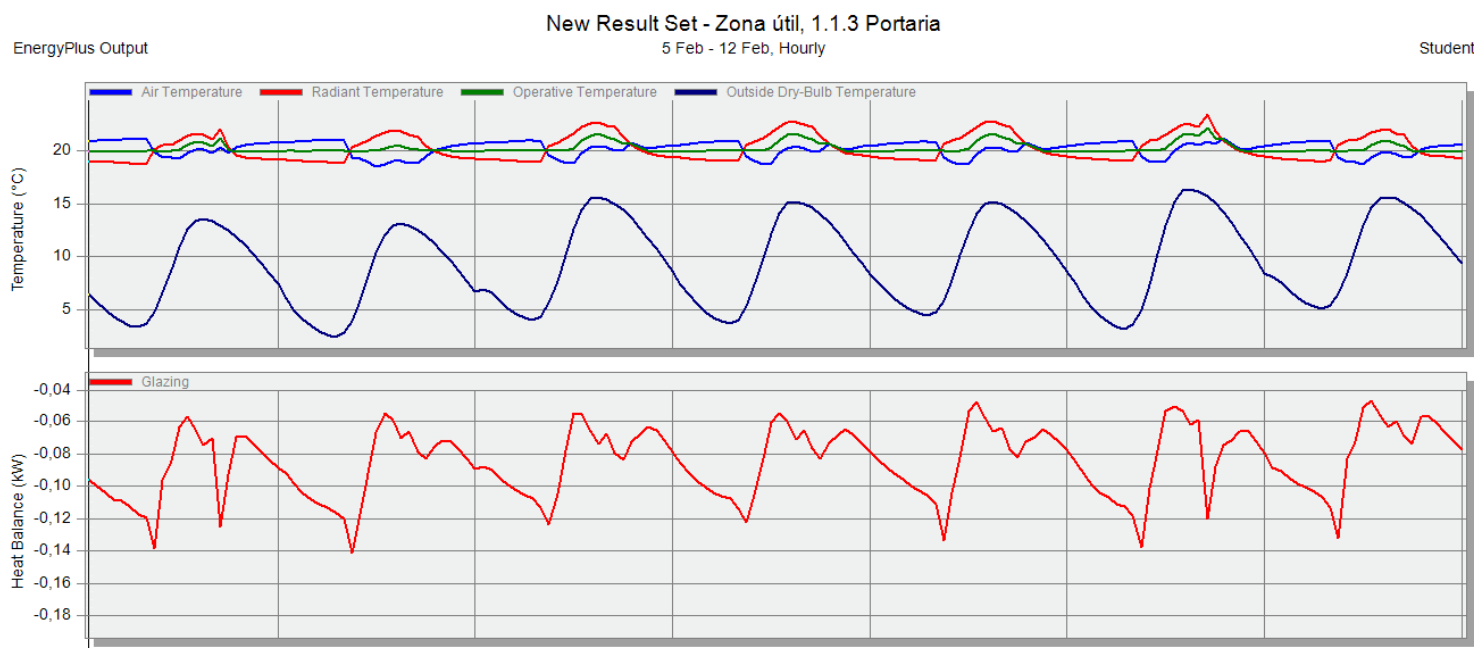

Tabela 2 - Comparação entre os coeficientes U de referência e máximo para a região I2/V2 e o U de desempenho mais desfavorável da envoltória opaca do edifício

\begin{tabular}{|c|c|c|c|}
\hline & $\mathrm{U}_{\text {ref }}\left(\mathrm{W} \cdot \mathrm{m}^{-2} \cdot{ }^{\circ} \mathrm{C}^{-1}\right)$ & $U_{\text {máx }}\left(W \cdot m^{-2} .{ }^{0} C^{-1}\right)$ & $\mathrm{U}_{\text {ESAN }}\left(\mathrm{W} \cdot \mathrm{m}^{-2} \cdot{ }^{0} \mathrm{C}^{-1}\right)$ \\
\hline Paredes & 0,60 & 1,60 & 0,505 \\
\hline Cobertura & 0,45 & 1,00 & 0,335 \\
\hline Piso & 0,45 & 1,00 & 0,922 \\
\hline
\end{tabular}

Tabela 3 - Consumo anual antes e depois do aumento de isolamento na laje de concreto

\begin{tabular}{l|c|c|c}
\hline & Antes (kWh) & Depois (kWh) & Diferença (\%) \\
\hline Circulação 2 & 1571 & 1692 & 7,1 \\
Salas 1.7.6-12 & 333 & 367 & 10 \\
Biblioteca & 201 & 236 & 17 \\
\hline
\end{tabular}

\section{Iluminação}

O controle da iluminação (garantida quase exclusivamente por lâmpadas T5 fluorescentes) é realizado de forma manual na portaria e na biblioteca. No entanto, no momento do estudo, o controle manual da iluminação interior foi constatado nas zonas de circulação, apesar da incidência de luz natural, causando aquecimento, maior consumo energético e diminuição da duração das lâmpadas.

Segundo Almeida et al. (2007), é possível melhorar o controle do sistema de iluminação artificial em função da insuficiência de luz natural. Essa é uma medida simples, de baixo custo, dado que o edifício 
já dispõe de sistemas de controle. Outra solução proposta por Almeida et al. (2007) é o fato de as lâmpadas fluorescentes serem inadequadas para compartimentos utilizados de forma intermitente, como, por exemplo, nos espaços sanitários, devido à diminuição do tempo de vida útil das lâmpadas. Nesse caso, a sugestão é de utilizar, por exemplo, lâmpadas de LED de qualidade e com números maiores de ciclos de acendimento.

Constata-se que a soma da potência das lâmpadas das áreas de circulação é de 5,97 kW. Admitindo-se que as lâmpadas estão acesas 11 horas por dia (9h20h), isso representa um consumo diário de 65,67 kWh. No entanto, apenas seria necessário ligá-las cerca de 4 a 5 horas por dia de inverno, poupando 7 horas, ou seja, 41,79 kWh, que se traduziria em uma economia de cerca de 5 euros por dia, a um valor unitário de 0,12 €.kWh ${ }^{-1}$ (ENTIDADE..., 2019). Considerando-se um consumo mensal de 21 dias úteis, a economia seria de, no mínimo, 105 euros mensais, o que constatamos ser suficiente para pagar, em média, a fatura de eletricidade em dois apartamentos unifamiliares em Portugal. Em nível de emissões de poluentes, em quilogramas equivalentes de dióxido de carbono $\left(\mathrm{kgCO}_{2} \mathrm{e}\right)$, e considerando um fator de emissão de 327 gCO $_{2} \mathrm{e} . \mathrm{kWh}^{-1}$ (GALP..., 2016), diariamente haveria uma redução de emissões na ordem de 13,7 $\mathrm{kgCO}_{2} \mathrm{e}$, ou $288 \mathrm{kgCO}_{2} \mathrm{e}$ mensais.

\section{Qualidade de Ar Interior (QAI)}

Relativamente à QAI, foi possível verificar alguns problemas, notadamente relativos à umidade do ar na zona do bar e de odores desagradáveis em algumas salas, que podem ser provenientes dos ralos. Em relação à zona do bar, que se comunica com os corredores, existe uma única grelha de extração de tamanho reduzido, afastada da área do banho-maria (para manter a temperatura das refeições e onde é aquecida água durante toda a manhã) com grande dissipação de vapor (Figura 10a). A cozinha não tem qualquer abertura para o exterior, apenas uma pequena grelha de ventilação, com pouca manutenção (Figura 10b).

A QAI poderia ser melhorada com instalação de uma grelha de extração de ar sobre o banho-maria, impedindo o excesso de umidade. Ao nível da cozinha a abertura de uma pequena janela ao exterior melhoraria a renovação de ar no ambiente anterior. Outra forma de atenuar o problema da QAI é fazer uma manutenção regular das grelhas e dos dutos de ventilação, de forma a promover a renovação higiênica de ar nos ambientes internos. Com o intuito de reduzir as fontes de odores desagradáveis em salas específicas, sugere-se a instalação de sifões no sistema de esgoto, assim como incrementar a taxa de renovação de ar nas salas, a fim de reduzir e/ou diluir os poluentes no ar em níveis aceitáveis (AGÊNCIA..., 2009).

\section{Água Quente Sanitária (AQS)}

No que concerne à $A Q S$, verificou-se que apesar da instalação de painéis solares no lado leste do edifício, onde estão os banheiros, estes não são, em geral, utilizados, pela falta de demanda de água quente. Nas torneiras das instalações sanitárias, localizadas ao lado desses banheiros, junto às oficinas, não existe dispositivo de água quente, nem a respectiva canalização desse serviço. Já no extremo do lado oeste (oposto) do edifício, onde está situado o bar e há necessidade de consumo significativo de água quente, o aquecimento é feito apenas por um cilindro termoacumulador, através de efeito de Joule. Existem também outras salas com dispositivos de água quente, como os banheiros dos laboratórios (salas 1.4 .7 e 1.4.8). Ainda faz parte do sistema um dissipador de calor ativo (que consome energia elétrica), para impedir que a temperatura da água ultrapasse os $90^{\circ} \mathrm{C}$. Essa situação acontece especialmente nos períodos de férias, em que o edifício não é utilizado e não há consumo de água quente.

\section{Figura 10 - (a) Grelha de ventilação única próxima do bar, na zona de refeições; e (b) grelha de} ventilação da cozinha

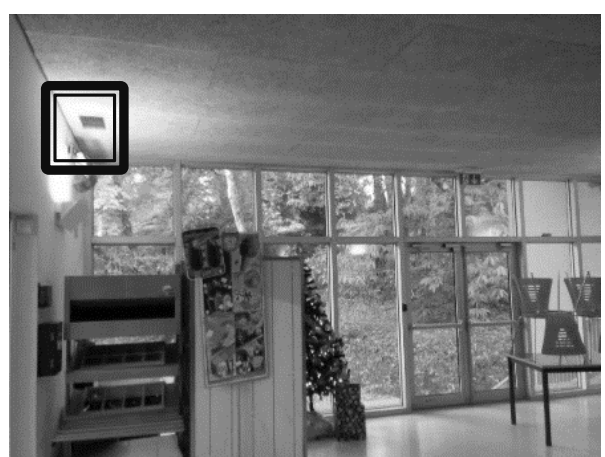

(a)

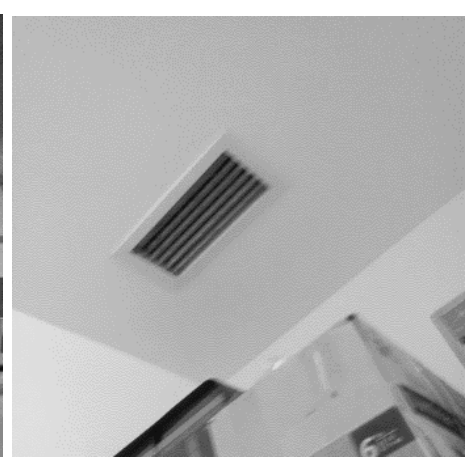

(b) 
Sugere-se o deslocamento dos painéis solares a serem instalados próximos à cafeteria (Figura 11), para que os dispositivos sejam aproveitados de forma eficiente com melhor exposição à incidência solar. Espera-se com essa solução reduzir os consumos com energia elétrica para aquecimento de água e, além disso, economizar energia para alimentar a ventoinha do dissipador de calor dos painéis solares. O efeito dessas soluções propostas não foi simulado, pelo fato de não se ter conhecimento do consumo real de AQS no edifício. No entanto, salienta-se que cada termoacumulador tem uma potência mínima e máxima de 26 kW e 44 $\mathrm{kW}$, respectivamente.

\section{Considerações finais}

Este estudo concretizou a avaliação energética do edifício da ESAN, tendo-se obtido resultados que levaram à proposta de medidas para a correção de deficiências no edifício. Assim, na fase inicial, recolheram-se os dados relativos à geometria e à composição da envoltória do edifício, sistemas de iluminação e equipamentos de climatização. A geometria do edifício foi modelizada com sucesso, através da interface gráfica da ferramenta DesignBuilder.

Embora não tenha sido possível calibrar o modelo de edifício (nem, consequentemente, determinar a classe de energética do edifício), pelo fato de não existirem dados relativos ao histórico de consumos de energia na época dessa avaliação, os resultados da avaliação da eficiência energética sugerem que a potência dos equipamentos de climatização instalados no edifício é suficiente para aquecer e insuficiente para arrefecer as instalações, sendo que o diferencial entre a potência necessária e a potência nominal dos equipamentos excede os $60 \mathrm{~kW}$ nos dois casos. Uma gestão automatizada da distribuição do calor no edifício (através da instalação de um sistema de controle eletrônico da temperatura) poderia melhorar significativamente essa situação.

Uma forma de diminuir o excesso de ganhos solares na fachada sul e com o arrefecimento do edifício quando o sistema não consiga manter as temperaturas de conforto seria a aplicação de venezianas exteriores nas fachadas do edifício. Os resultados mostram que o problema de heterogeneidade das áreas envidraçadas causa, em duas salas contíguas avaliadas, uma diferença de ganhos solares de 6 a 7 vezes, nos períodos de verão e inverno. Exemplificando, a simulação do uso de dispositivos de proteção solar nas fachadas demonstra uma redução da temperatura do ar interior de $12{ }^{\circ} \mathrm{C}$ no local da portaria, localizada na fachada sul.

Em relação à envoltória opaca, os resultados mostram, em geral, um bom isolamento térmico, com exceção da laje de concreto do piso, que possui um coeficiente de transmissão térmica de $U=0,922$ $\mathrm{W} . \mathrm{m}^{-2} \cdot{ }^{\circ} \mathrm{C}^{-1}$, valor superior aos coeficientes das paredes e da cobertura. Estimou-se que triplicando a espessura do isolamento, diminuiria até $17 \%$ as transferências de calor pelo piso radiante do edifício.

Quanto à iluminação, é proposto um sistema de controle automático das lâmpadas na área de circulação. Esse sistema poderia favorecer uma economia mensal de 105 euros e $288 \mathrm{~kg}$ equivalentes de $\mathrm{CO}_{2}$. Além disso, o tempo de vida das lâmpadas aumentaria substancialmente. Constata-se também o fato de os painéis solares de AQS estarem colocados em uma zona do edifício onde não há necessidade de água quente, provocando um desperdício de energia, devido ao sistema de segurança ativo, que impede a água de mudar de fase nos dutos. Na zona do edifício onde há consumo de água quente funciona um termoacumulador elétrico, com potência elevada e baixa eficiência energética.

\section{Figura 11 - Proposta de deslocamento dos painéis solares para atender às necessidades de uso de AQS da cafeteria}

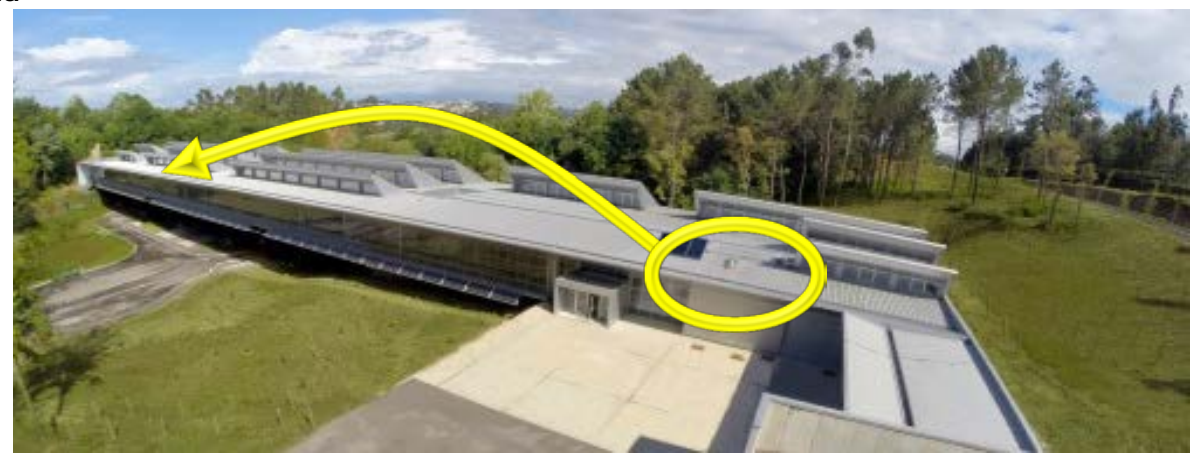

Fonte: ESAN (ESCOLA..., 2016). 
Conclui-se que o edifício, apesar de ser recente e de cumprir a legislação, a respeito de materiais de construção utilizados nas envoltórias, não possui um desempenho energético que lhe atribuiria uma classe energética favorável, caso isso tivesse sido realizado neste estudo. Uma sugestão para um futuro trabalho nesse edifício seria utilizar o modelo de simulação criado, atualizando a sua caracterização, tendo em conta diferentes equipamentos ou perfis de ocupação do edifício e, com dados históricos de consumos de energia elétrica, determinar a classe energética do edifício. Com esse elemento poderiam ser apontados os regulamentos que estão a ser contraordenados.

Quanto à regulamentação (europeia e portuguesa), pode-se referir que é ambiciosa e exigente, porém não é fiscalizada de forma eficiente. No caso específico de Portugal, os projetos de novos edifícios e de grandes reabilitações têm de ser aprovados e vistoriados por peritos qualificados pela ADENE, porém esse processo de licenciamento não é aplicado a edifícios estaduais, dado que para esses não são necessárias autorizações de outras entidades. Deve-se, por isso, alterar essa situação urgentemente, uma vez que os consumos energéticos desnecessários nos edifícios públicos são um passivo ambiental, representam custos de operação pagos pelos contribuintes, representam um peso importante no orçamento de um governo e, além disso, deveriam ser os primeiros a cumprir as regras exigidas aos cidadãos, divulgando a construção eficiente como algo economicamente viável, confortável e apelativo.

Finalizando, este estudo poderá servir de base em análises energéticas de diversas tipologias de construções, tendo impacto sobre as escolhas que poderão ser feitas durante as fases de desenvolvimento do projeto de novos edifícios, notadamente em climas temperados (caso de Portugal) ou climas subtropicais (caso dos estados do Paraná, Santa Catarina e Rio Grande do Sul, na Região Sul do Brasil), que apresentam estações quente e fria bem definidas. Isso pode ser um desafio, pois as soluções adequadas em uma estação poderão ocasionar problemas em outra. Salienta-se que os estudos de eficiência energética devem ser realizados na fase da elaboração do projeto de construção dos edifícios, em edifícios públicos e privados, evitando-se correções e custos adicionais posteriores. Observa-se ainda que o aumento da eficiência energética dos edifícios, aliado a uma redução das emissões de dióxido de carbono, contribui para o uso de soluções ambientais passivas e para a redução do "efeito estufa".

\section{Referências}

AGÊNCIA PORTUGUESA DO AMBIENTE. Qualidade do Ar em Espaços Interiores: um guia técnico. Amadora: APA, 2009.

ALMEIDA, A. T. D. et al. Manual Técnico de Gestão de Energia. Coimbra: Universidade de Coimbra; MVV Consulting GmbH, 2007.

Disponível em:

$<$ https://www.researchgate.net/publication/270577 270>. Acesso em: 08 jul. 2019.

\section{BUILDINGS PERFORMANCE INSTITUTE} EUROPE. 97\% of Buildings in the EU Need to be Upgraded. 2014. Disponível em: $<$ http://bpie.eu/publication/97-of-buildings-in-theeu-need-to-be-upgraded/> . Acesso em: 08 jul. 2019.

CHAMA- EQUIPAMENTOS TÉRMICOS, S.A. Parque do Cercal - Circuitos das Lajes Activas - Telas Finais. Oliveira de Azeméis. 2013.

COMISSÃO EUROPEIA. Directiva 2010/31/UE do Parlamento Europeu e do Conselho, de 19 de maio de 2010, relativa ao desempenho energético dos edifícios. Official Journal of the European Union, 2010.

COMISSÃO EUROPEIA. Heating and Cooling. 2016a. Disponível em:

<https://ec.europa.eu/energy/en/topics/energyefficiency/heating-and-cooling>. Acesso em: 08 jul. 2019.

\section{COMISSÃO EUROPEIA. Proposal For a} Directive of the European Parliament and of the Council amending Directive 2010/31/EU on the Energy Performance of Buildings. Brussels, $2016 b$.

DESIGNBUILDER. DesignBuilder Help: editing zone heated floor data. 2016. Disponível em: <http://www.designbuilder.co.uk/helpv5.0/\#Detail ed_HVAC/Editing_Zone_Heated_Floor.htm\%3FT ocPath\%3DBuilding\%2520Models\%7CDetailed\% 2520HVAC\%7CHVAC\%2520Component\%2520 Data\%7CZone\%2520Unit\%2520Data\%7CHeated \%2520Floor\%2520Data\%7C___ 0>. Acesso em: 08 jun. 2016.

\section{DIRECÇÃO-GERAL DE ENERGIA E} GEOLOGIA. Estatísticas e Preços: principais indicadores energéticos. Lisboa, 2016.

ENERES - Sistemas Energéticos Sostenibles. Memória Técnica do Sistema de Climatização por Troca Geotérmica, Bomba de Calor Geotérmica e Lajes Termoactivas. Oliveira de Azeméis. 2010. 
ENTIDADE REGULADORA DOS SERVIÇOS ENERGÉTICOS. Tarifas Transitórias de Venda a Clientes Finais em Portugal Continental. 2019. Disponível em: <http://www.edpsu.pt/pt/EDP\%20Docs/Tarifas\%2 0Transitórias\%20não\%20BTN\% 202019.pdf>. Acesso em: 13 jan. 2019.

ESCOLA SUPERIOR AVEIRO NORTE. [Esan_0.jpg; mapa_Esan.png]. 2016. Disponível em: <http://www.ua.pt/esan/>. Acesso em: 15 jun. 2019.

FIRLĄG, S.; PIASECKI, M. NZEB Renovation Definition in a Heating Dominated Climate: case study of Poland. Applied Sciences, v. 8, n. 9, p. 1605, 2018.

GALP ENERGIA. A Nossa Energia. 2016. Disponível em: <http://www.galpenergia.com /PT/ProdutosServicos/Produtos/Eletricidade/Centr o-de-informacao/A-nossa-Energia/Paginas/Anossa-Energia.aspx>. Acesso em: 15 out. 2016.

INSTITUTO NACIONAL DE ESTATÍSTICA. Fogos Concluídos (N..$^{\circ}$ ) em Construções Novas Para Habitação Familiar por Localização Geográfica e Entidade Promotora. 2018.

INSTITUTO NACIONAL DE ESTATÍSTICA. Idade Média dos Edifícios (Ano) por Localização Geográfica (à data dos Censos 2011). 2011.

INSTITUTO NACIONAL DE ESTATÍSTICA; DIRECÇÃO-GERAL DE ENERGIA E GEOLOGIA. Inquérito ao Consumo de Energia no Sector Doméstico. 2010.

KAPLAN, M. et al. Reconciliation of a DOE2.1c Model With Monitored End-Use Data From a Small Office Building. ASHRAE Transactions, v. 96, n. 1, 1992.

KURNITSKI, J. Technical Definition for Nearly Zero Energy Buildings. REHVA - Federation of European Heating, Ventilation and Air Conditioning. 2013. Disponível em: $<$ http://www.rehva.eu/publications-andresources/rehva-journal/2013/032013/technicaldefinition-for-nearly-zero-energy-buildings.html> . Acesso em: 09 ago. 2019.
LABORATÓRIO NACIONAL DE ENGENHARIA GEOLÓGICA. CLIMAS-SCE Software para o Sistema Nacional de Certificação de Edifícios. 2013. Disponível em: $<$ http://www. lneg.pt/servicos/328/2263/>. Acesso em: 18 out. 2018.

O'NEILL, Z.; EISENHOWER, B. Leveraging the Analysis of Parametric Uncertainty for Building Energy Model Calibration. Building Simulation, v. 6, n. 4, p. 365-377, 2013.

PASSIVHAUS INSTITUT. Passipedia: the passive house resource. 2016. Disponível em: <https://passipedia.org>. Acesso em: 19 out. 2018.

POWER, A. Does Demolition or Refurbishment of Old and Inefficient Homes Help to Increase Our Environmental, Social and Economic Viability? Energy Policy, v. 36, n. 12, p. 4487-4501, 2008.

PRATT, R. G. Errors in Audit Predictions of Commercial Lighting and Equipment Loads and in Their Impacts on Heating and Cooling Estimates. ASHRAE Transactions, v. 96, n. 2, 1990.

STANIASZEK, D. et al. Renovation Strategies of Selected EU Countries: A Status Report on Compliance with Article 4 of the Energy Efficiency Directive. Buildings Performance Institute Europe (BPIE): Brussels, Belgium, 2014.

TAN, Y. et al. Green Retrofit of Aged Residential Buildings in Hong Kong: a preliminary study. Building and Environment, v. 143, p. 89-98, 2018.

YOON, J.; LEE, E. J.; CLARIDGE, D. E. Calibration Procedure for Energy Performance Simulation of a Commercial Building. Journal of Solar Energy Engineering, v. 125, n. 3, p. 251257, 2003. 
J osé Carlos Martins Ramalho

Departamento de Engenharia Mecânica | Universidade de Aveiro | Campus Universitário de Santiago | Aveiro - Portugal | 3810-193 | Tel. +55 (27) 98893-4188 | E-mail: jcramalho@ua.pt

\section{Nelson Amadeu Dias Martins}

Departamento de Engenharia Mecânica | Universidade de Aveiro | E-mail: nmartins@ua.pt

Revista Ambiente Construído

Associação Nacional de Tecnologia do Ambiente Construído

Av. Osvaldo Aranha, 99 - 3o andar, Centro

Porto Alegre - RS - Brasil

CEP $90035-190$

Telefone: +55 (51) 3308-4084

Fax: +55 (51) 3308-4054

www. seer. ufrgs. br/ ambienteconstruido

E-mail: ambienteconstruido@ufrgs.br

(c) (1) This is an open-access article distributed under the terms of the Creative Commons Attribution License. 